\title{
Characterization and Atmospheric Implication of Hydrotrioxy Radical-Water-Methylamine-Formic Acid-Sulphuric Acid Complexes
}

\author{
Matjaž Dlouhy and Antonija Lesar* \\ Department of Physical and Organic Chemistry, Jožef Stefan Institute, Jamova c. 39, SI-1000 Ljubljana, Slovenia \\ *Corresponding author: E-mail: antonija.lesar@ijs.si \\ Received: $10-26-2018$
}

Presented at the $24^{\text {th }}$ Annual Meeting of the Slovenian Chemical Society

\begin{abstract}
New particle formation is an important source of atmospheric aerosols, but the nucleation phenomena is still poorly understood. Here the formation of bimolecular complexes of $\mathrm{HOOO}$ r radical with $\mathrm{H}_{2} \mathrm{O}, \mathrm{CH}_{3} \mathrm{NH}_{2}, \mathrm{HCOOH}$ and $\mathrm{H}_{2} \mathrm{SO}_{4}$ has been investigated by quantum chemical methods. The stabilising effect of methylamine is found to be close to that of sulphuric acid, both complexes are formed spontaneously at studied atmospheric conditions. In addition, the hydration of the four most stable 1:1 complexes forming the 1:1:1 complexes have been considered. Water stabilises a $\mathrm{HOOO}^{\circ} \ldots \mathrm{H}_{2} \mathrm{SO}_{4}$ complex, the most effectively. Complexation process is spontaneous as well. Complex formations induced significant red-shift and enhancement of the IR intensity for the $\mathrm{OH}$ stretching vibration relative to that of the free radical. Equilibrium constants have been examined and the relative abundance of complexes in the troposphere is discussed.
\end{abstract}

Keywords: Hydrotrioxy radical; atmospheric acids; amine; water; nucleation precursors; quantum chemistry

\section{Introduction}

Hydrotrioxy (HOOO*) radical, or hydridotrioxygen according to IUPAC nomenclature, ${ }^{1}$ belongs to the group of polyoxides with general molecular formula, $\mathrm{RO}_{n} \mathrm{R}$, where $\mathrm{R}$ stands for hydrogen, any other atom or chemical group and $n \geq 3 .^{2,3}$ It is believed that such polyoxides, especially the $\mathrm{HOOO}^{*}$ radical, play an important role in atmospheric processes in Earth's troposphere and environmental reactions as well as in biological oxidation reactions. ${ }^{4}$ Hence the understanding of its structure, stability and reactivity with other atmospheric species is a matter of the utmost importance.

The HOOO ${ }^{\circ}$ radical can be regarded as an adduct of $\mathrm{HO}^{*}$ and $\mathrm{O}_{2}$, and represents a temporary reservoir of $\mathrm{OH}^{*}$ radicals. ${ }^{5}$ Many theoretical and experimental data suggest that the formation of $\mathrm{HOOO}^{*}$ radical in the atmosphere can be described by the following reactions $s^{5,6}$ :

$$
\begin{aligned}
& \mathrm{HOO}^{\bullet}+\mathrm{O} \rightarrow \mathrm{HOOO}^{\bullet} \\
& \mathrm{H}^{\bullet}+\mathrm{O}_{3} \rightarrow \mathrm{HOOO}^{\bullet} \\
& \mathrm{HO}^{\bullet}+\mathrm{O}_{2} \rightarrow \text { HOOO} \bullet
\end{aligned}
$$

Reaction 3 is exothermic with the activation energy of around $3 \mathrm{kcal} \mathrm{mol}^{-1}$ implying that a certain amount of the radical is indeed formed. ${ }^{6}$

The first mention of the hydrotrioxy radical dates back to the 1970's and ever since it has been a subject of pomum Eridis. ${ }^{7}$ Despite its long postulated existence, the HOOO• radical was inadvertently predicted in 1996 by Speranza $^{8}$ and was first detected three years later by Cacace et al. ${ }^{9}$ in the gas phase experiments based on neutralization-reionization/collisionally activated dissociation mass spectrometry. At the turn of the millennium, Nelander et al. ${ }^{10}$, investigated and detected $\mathrm{HOOO}^{*}$ radical in argon matrices using infrared spectroscopy. A few years later, in 2005 Suma et al. ${ }^{11}$ reported the rotational spectrum and structure of the radical. Their experimental study was the first to confirm the planar geometry of the radical, suggesting trans- $\mathrm{HOOO}{ }^{*}$ conformation with inner $\mathrm{O}-\mathrm{O}$ bond length of $1.688 \AA$.

Numerous theoretical studies on the structure and stability of the radical have been published, but there is still no consensus on its planar structure (cis-HOOO* or trans$\left.\mathrm{HOOO}^{*}\right)$ as the quantum chemical calculations are strongly dependent on the level of theoretical method and basis sets used in the calculations. ${ }^{1,4,12,13,14}$ 
$\mathrm{HOOO}^{*}$ is a reactive molecule and can form complexes by interaction with other species present in the atmosphere. Recent works of Kim et al. ${ }^{15}$ show that the hydrated radical may be 20 to 500 times more stable compared to the isolated HOOO ${ }^{\bullet}$ structure. Furthermore, Cannon et al. ${ }^{16}$ have reported that the radical forms a stable binary and ternary complexes with water and sulphuric acid, which are up to 800 times more stable than the isolated radical.

Water is the most abundant species in the atmosphere, its concentration varies between $1-4 \%^{17}$, and can form strong hydrogen bonds with other molecules and radical species. Such interactions can lead to the formation of new atmospheric particles that serve as a predecessors of secondary aerosols. ${ }^{18,19}$ In addition to the water, sulphuric acid is the main molecular species in new particle formation. ${ }^{19}$ Many recent studies reported the importance of gaseous amines (especially methyl-, dimethyl- and trimethylamine) in nucleation processes. ${ }^{16}$ Nucleation is enhanced also by organic compounds, formic acid is an important trace constituent of the troposphere. ${ }^{18}$ The abundance of these species varies, but experimental data proposes that the concentration of sulphuric acid and methylamine is hovering around $1 \times 10^{7}$ molecule $\mathrm{cm}^{-3} 18,20$, while a concentration of formic acid is higher, around $2 \times 10^{11}$ molecule $\mathrm{cm}^{-3}{ }^{18}$. Their concentration can significantly increase in urban and industrial areas (up to a few orders of magnitude) and varies pretty much by daytime and season. ${ }^{20}$

In this paper we have performed a study on electronic structure calculations of possible conformations of the hydrotrioxy radical and its complexes with water, sulphuric acid, methylamine and formic acid molecules. Further, the hydration of the most stable 1:1 complexes were investigated. Based on these calculations, we reported valuable properties of complexes, such as the equilibrium structure, stability, the nature of interaction between each component and the IR spectral features. Thermodynamic properties of the clusters were calculated at four temperatures relevant to the atmospheric conditions. The computed Gibbs free energies were used to estimate the relative concentration of the formed complexes.

\section{Computational Methods}

All calculations were performed out with the GAUSSIAN 16 software package ${ }^{21}$ using default convergence criteria. Equilibrium geometry of monomers and complexes were optimised using the Becke three-parameter non-local exchange functional with the non-local correlation of Lee, Yang, and Parr (B3LYP) ${ }^{22,23}$ and the People-type $6-311++\mathrm{G}(3 \mathrm{df}, 3 \mathrm{pd})^{24}$ basis set. The harmonic and anharmonic frequencies of all species were computed at the same level of theory in order to confirm the nature of the stationary points. The final energies of the complexes were improved by a multi-step composite method using the CBS-QB3 level of theory. ${ }^{25}$ The selection of above methods was based on the comparison of test calculations for hydrotrioxy radical, and available experimental structural, spectroscopic and binding parameters. These calculations included B3LYP, M06-2X ${ }^{26}$ density functional methods and $\operatorname{CCSD}(\mathrm{T})$ wave function method ${ }^{27}$ in combination with the $6-311++\mathrm{G}(2 \mathrm{df}, 2 \mathrm{pd}), 6-311++\mathrm{G}(3 \mathrm{df}, 3 \mathrm{pd})$ and aug-cc-pVDZ basis sets. The results of these computations are summarised in the next section.

Binding energy $\left(D_{0}\right)$ of the complexes has been estimated as a negative difference between the zero-point corrected energy of the complexes $\left(E_{0 \text {, complex }}\right)$ and monomers $\left(E_{0, \text { monoi }}\right)$. Specifically, for three-body complex the equation is written as:

$$
D_{0}=-\left(E_{0, \text { complex }}-E_{0, \text { mono1 }}-E_{0, \text { mono2 }}-E_{0, \text { mono3 }}\right) \text {. }
$$

Thermochemical parameters, i.e. Gibbs free energies, are calculated at four atmospherically relevant conditions: at the surface, $298.15 \mathrm{~K}$ and $278.15 \mathrm{~K}$, 1atm; at altitude $5 \mathrm{~km}$, $255.15 \mathrm{~K}, 0.533 \mathrm{~atm}$ and at altitude $8 \mathrm{~km}, 235.15 \mathrm{~K}, 0.351$ atm. Further, the equilibrium constants, $K_{\mathfrak{c}}$, of the complex formations were calculated according to equation 5 :

$$
K_{\mathrm{c}}(T)=\sigma \frac{10^{3} R T}{N_{\mathrm{A}}} \mathrm{e}^{-\frac{\Delta G_{\mathrm{T}}}{R T}} .
$$

In this equation $\sigma$ is the symmetry number, $R$ is the universal gas constant, $T$ is the temperature, $N_{\mathrm{A}}$ is the Avogadro's number and $\Delta G_{\mathrm{T}}$ is the complex formation Gibbs free energy change.

\section{Results and Discussion}

Let us first consider the HOOO ${ }^{*}$ radical, the optimised structures of cis and trans conformations denoted as c-HTO and t-HTO, respectively, are presented in Figure 1 with the atom enumeration. Our calculations confirm that both conformations exhibit planar geometry. Due to a very low isomerization energy barrier the rotation around inner $\mathrm{O}^{2}-\mathrm{O}^{3}$ bond is nearly spontaneous.
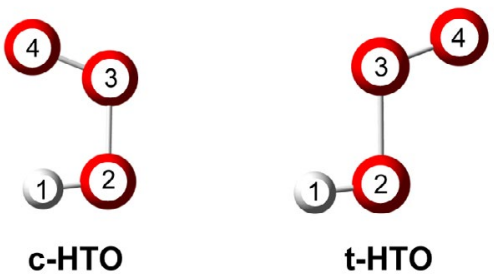

Figure 1: Optimised structures of cis-HOOO ${ }^{*}(\mathrm{c}-\mathrm{HTO})$ and transHOOO• (t-HTO) configuration of radical.

Structural parameters obtained at different levels of theory are summarised in Table 1. Calculated values for bond lengths and angles are in good agreement with available experimental data also presented in the Table. In general, c-HTO has longer bond lengths and narrower angles in 
Table 1: Optimised geometry parameters for c-HTO and t-HTO. Bond distances are given in Å and angles in degrees. For comparison, experimental data are included.

\begin{tabular}{lccccc}
\hline & & \multicolumn{5}{c}{$\mathbf{c}-\mathbf{H} \mathbf{T} \mathbf{c}$} \\
Method/basis set: & $\boldsymbol{d}\left(\mathbf{H}^{\mathbf{1}} \mathbf{O}^{\mathbf{2}}\right)$ & $\boldsymbol{d}\left(\mathbf{O}^{\mathbf{2}} \mathbf{O}^{\mathbf{3}}\right)$ & $\boldsymbol{d}\left(\mathbf{O}^{\mathbf{3}} \mathbf{O}^{\mathbf{4}}\right)$ & $\boldsymbol{a}\left(\mathbf{H}^{\mathbf{1}} \mathbf{O}^{\mathbf{2}} \mathbf{O}^{3}\right)$ & $\boldsymbol{a}\left(\mathbf{O}^{\mathbf{2}} \mathbf{O}^{3} \mathbf{O}^{4}\right)$ \\
\hline M06-2X/aug-cc-pVTZ & 0.973 & 1.434 & 1.251 & 100.8 & 111.6 \\
B3LYP/aug-cc-pVTZ & 0.974 & 1.505 & 1.250 & 99.9 & 112.7 \\
B3LYP/6-311++G(2df,2pd) & 0.973 & 1.503 & 1.249 & 100.0 & 112.7 \\
B3LYP/6-311++G(3df,3pd) & 0.973 & 1.501 & 1.247 & 99.9 & 112.7 \\
CCSD(T)/ aug-cc-pVTZ & 0.973 & 1.500 & 1.241 & 99.8 & 111.9 \\
\hline & & & $\mathbf{t}-\mathbf{H T O}$ & & \\
\hline M06-2X/aug-cc-pVTZ & 0.969 & 1.458 & 1.240 & 100.0 & 109.4 \\
B3LYP/aug-cc-pVTZ & 0.971 & 1.546 & 1.233 & 98.5 & 110.2 \\
B3LYP/6-311++G(2df,2pd) & 0.970 & 1.454 & 1.232 & 98.6 & 110.2 \\
B3LYP/6-311++G(3df,3pd) & 0.970 & 1.544 & 1.230 & 98.6 & 110.2 \\
CCSD(T)/ aug-cc-pVTZ & 0.970 & 1.542 & 1.231 & 100.2 & 109.1 \\
experiment $^{\mathrm{a}}$ & 0.913 & 1.684 & 1.235 & 92.4 & 110.7 \\
experiment $^{\mathrm{b}}$ & 0.972 & 1.688 & 1.225 & 90.0 & 111.0 \\
experiment $^{\mathrm{c}}$ & 0.970 & - & 1.208 & - & - \\
\hline
\end{tabular}

${ }^{a}$ McCathy et al., FTMW spectrometry ${ }^{1}$, b Suma et al., FTMW spectrometry ${ }^{11}$, ${ }^{c}$ Huber et al., Photoionization mass spectrometry ${ }^{28}$

comparison to the same parameters in t-HTO. Interestingly, for inner $\mathrm{O}^{2}-\mathrm{O}^{3}$ bond length we detected largest differences between calculated and experimental values, absolute deviation is between $0.14 \AA$ and $0.25 \AA$. Calculations at B3LYP/ 6-311++G(3df,3pd) show good agreement with available experimental data for $\mathrm{t}-\mathrm{HTO}$, even for the most variable inner bond length, with a discrepancy of around $8 \%$.

Calculated binding energies for both stable conformations of the radical are represented in Table 2. The energy difference between them is rather small, but $D_{0}$ is strongly dependent on the method and basis set used for calculations. Results computed at M06-2X/aug-cc-pVTZ level show no correlation between experimental and computed value. Pople's B3LYP method, CCSD(T) method and CBS-QB3 composite method show a stronger correlation with the experiment, with the latter being the most reliable. At the CBS-QB3 level of calculation t-HTO is slightly more stable, by $0.12 \mathrm{kcal} \mathrm{mol}^{-1}$, than the cis conformation. The predicted energy difference is at the limit of computational accuracy, and for this reason, we decided to take both stable conformations into account in our study.

Table 2: Binding energies ( $\mathrm{D}_{0}$; eq. 4$)$ in $\mathrm{kcal} \mathrm{mol}^{-1}$ for $\mathrm{c}-\mathrm{HTO}$ and t-HTO.

\begin{tabular}{lcc}
\hline Method/basis set: & c-HTO & t-HTO \\
\hline M06-2X/aug-cc-pVTZ & 1.23 & 1.36 \\
B3LYP/aug-cc-pVTZ & 3.07 & 3.20 \\
B3LYP/6-311++G(2df,2pd) & 2.82 & 2.94 \\
B3LYP/6-311++G(3df,3pd) & 2.80 & 2.88 \\
CCSD(T)/ aug-cc-pVTZ & 2.71 & 2.83 \\
CBS-QB3 & 2.69 & 2.81 \\
experiment $^{\text {a }}$ & - & 2.94
\end{tabular}

a Picard et al., CRESU experiment ${ }^{29}$
Harmonic and anharmonic frequencies for both configurations of the radical along with the IR absorption intensities at the B3LYP/6-311++G(3df,3pd) level of theory are presented in Table 3 and graphically illustrated in Figures S1 and S2 of Supplementary Material. The radical has six different vibrational modes. The comparison between calculated harmonic and anharmonic vibrational frequencies shows that $\mathrm{OH}$ stretching absorption peaks for t-HTO and c-HTO differ for $160 \mathrm{~cm}^{-1}$ and $166 \mathrm{~cm}^{-1}$, respectively; while all the others are shifted to higher energies on average by $24 \mathrm{~cm}^{-1}$ in t-HTO and $31 \mathrm{~cm}^{-1}$ in $\mathrm{c}$-HTO. Calculated anharmonic frequencies for $\mathrm{t}-\mathrm{HTO}$ and c-HTO show reasonable agreement with observed gas-phase spectra. Predicted HO stretching peak in t-HTO appears $13 \mathrm{~cm}^{-1}$ lower than experimentally observed; implying that the calculated $\mathrm{OH}$ stretching mode for the complexes should be adequate. The differences between anharmonic and experimental values for other vibrations are slightly more significant.

\subsection{Structure, Intramolecular Interaction and Binding Energy}

\section{Binary complexes}

A systematic sampling was used to search for global minima of the complexes. Nearly a hundred initial guess structures were generated where all rational interaction of radical with water (W), methylamine (MA), formic acid (FA) and sulphuric acid (SA) molecules were considered. After full geometry optimization and on the basis of the Boltzmann probability distributions two stable low-energy structures for the HTO-W, two for HTO-MA, six for HTOFA and three for HTO-SA complexes were identified. All these structures are shown in Supplementary Material, Figure S3, while the most stable structure for each type of com- 
Table 3: B3LYP/6-311++G(3df,3pd) calculated harmonic and anharmonic frequencies $(v)$ in $\mathrm{cm}^{-1}$ and IR absorption intensities (I) in $\mathrm{km} \mathrm{mol}^{-1}$ of c-HTO and t-HTO. Available experimental values are given.

\begin{tabular}{llccccc}
\hline & & \multicolumn{2}{c}{ harmonic } & \multicolumn{2}{c}{ anharmonic } & experimenta \\
& Mode: & $\boldsymbol{v}$ & $\mathbf{I}$ & $\boldsymbol{v}$ & $\mathbf{I}$ & $\boldsymbol{v}$ \\
\hline t-HTO & $\mathrm{H}^{1} \mathrm{O}^{2}$ srt. & 3742 & 70 & 3582 & 59 & 3569 \\
& $\mathrm{O}^{3} \mathrm{O}^{4}$ str. & 1389 & 22 & 1353 & 36 & - \\
& $\mathrm{H}^{1} \mathrm{O}^{2} \mathrm{O}^{3}$ bend. & 1239 & 136 & 1199 & 113 & 1202 \\
& $\mathrm{O}^{2} \mathrm{O}^{3} \mathrm{O}^{4}$ bend. & 659 & 64 & 636 & 53 & 482 \\
& $\mathrm{O}^{2} \mathrm{O}^{3}$ str. & 460 & 76 & 445 & 74 & 244 \\
& $\mathrm{H}^{1} \mathrm{O}^{2} \mathrm{O}^{3} \mathrm{O}^{4}$ tor. & 183 & 109 & 193 & 98 & 129 \\
\hline c-HTO & $\mathrm{H}^{1} \mathrm{O}^{2}$ srt. & 3687 & 49 & 3521 & 42 & - \\
& $\mathrm{O}^{3} \mathrm{O}^{4}$ str. & 1413 & 72 & 1362 & 72 & - \\
& $\mathrm{H}^{1} \mathrm{O}^{2} \mathrm{O}^{3}$ bend. & 1240 & 12 & 1219 & 8 & - \\
& $\mathrm{O}^{2} \mathrm{O}^{3} \mathrm{O}^{4}$ bend. & 715 & 150 & 691 & 138 & - \\
& $\mathrm{O}^{2} \mathrm{O}^{3}$ str. & 463 & 19 & 450 & 22 & 148 \\
& $\mathrm{H}^{1} \mathrm{O}^{2} \mathrm{O}^{3} \mathrm{O}^{4}$ tor. & 230 & 106 & 163 & 93 & \\
\hline
\end{tabular}

${ }^{a}$ Murray et al., values for isolated radical in gas-phase ${ }^{30}$

plex is illustrated in Figure 2. The binding energies $D_{0}$, are given in the figure to present the complex's stability.

$c-H T O-W$ complex. After complexation a planar structure of radical moiety in the complex is preserved. The inner $\mathrm{O}-\mathrm{O}$ bond in the radical unit is shortened by $0.03 \AA$ compared to that in the isolated radical. The hydrogen atom from the radical and the electron rich oxygen atom from the water molecule form one strong H-bond with the length of $1.782 \AA$. Our calculated binding energy for this structure is $4.80 \mathrm{kcal} \mathrm{mol}^{-1}$, which is in good agreement with the previously reported value of $4.86 \mathrm{kcal} \mathrm{mol}^{-1}$ by Kim et al. ${ }^{15}$

c-HTO-MA complex. The formation of a binary complex between c-HTO and MA forced the radical out of a planar geometry. The inner O-O bond in the c-HTO-MA complex is shortened by $0.04 \AA$ in comparison to the isolated radical. The hydrogen bond, $1.725 \AA$ in length, is formed between the hydrogen atom from the radical and the nitrogen atom of the methylamine. Binding energy of this complex is $9.85 \mathrm{kcal} \mathrm{mol}^{-1}$.

c-HTO-FA complex. Due to the interaction between c-HTO and FA, the radical moiety undergoes a structural change, its geometry in the complex is no longer planar and the inner bond is shortened by $0.05 \AA$. The complex is found to be of a cyclic structure with two H-bonds. A shorter hydrogen bond, $1.734 \AA$, is formed between the carbonyl oxygen atom of the formic acid and the hydrogen atom of the radical, but the radical can also act as a proton acceptor, resulting in a second $\mathrm{H}$-bond, $1.885 \AA$, with the acid proton. The calculated binding energy for this complex is $8.14 \mathrm{kcal} \mathrm{mol}^{-1}$.

$t$-HTO-SA complex. When $\mathrm{t}$-HTO interacts with SA, the inner $\mathrm{O}-\mathrm{O}$ bond in the HOOO moiety of the complex is by $0.03 \AA$ shorter than that in the free radical. Two H-bonds with the length of $1.790 \AA$ and $2.080 \AA$ are formed resulting in a cyclic structure with a planar t-HTO unit in the complex. In the shorter H-bond SA acts as a proton donor while in the second, rather longer $\mathrm{H}$-bond, the hydroxyl oxygen atom from the radical interacts with a lone oxygen electron pair of SA. Our calculated binding energy for this structure is $10.09 \mathrm{kcal} \mathrm{mol}^{-1}$, which is in good agreement with the previously reported value of $10.00 \mathrm{kcal}$ mol $^{-1}$ by Cannon et al. ${ }^{16}$

\section{Ternary complexes}

In addition, we carried out an extensive search of a possible structure of the ternary complexes formed by hy-

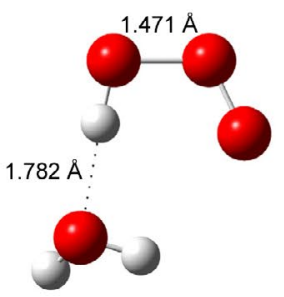

C-HTO-W

$D_{0}=4.80 \mathrm{kcal} \mathrm{mol}^{-1}$

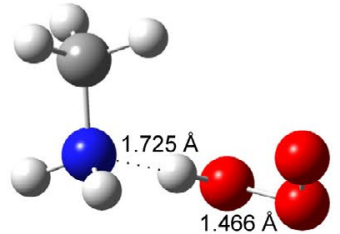

C-HTO-MA

$D_{0}=9.85 \mathrm{kcal} \mathrm{mol}^{-1}$

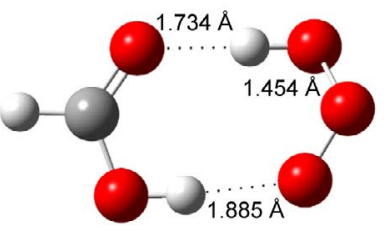

c-HTO-FA

$D_{0}=8.14 \mathrm{kcal} \mathrm{mol}^{-1}$

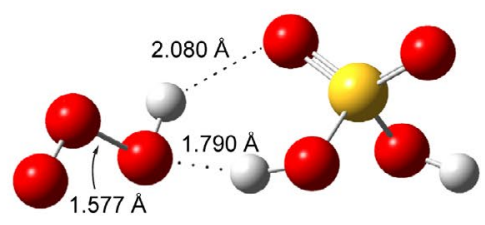

t-HTO-SA

$D_{0}=10.09 \mathrm{kcal} \mathrm{mol}^{-1}$

Figure 2: Optimised structures of the most stable c-HTO-W, c-HTO-MA, c-HTO-FA and t-HTO-SA complexes with the B3LYP/6-311++G(3d$\mathrm{f}, 3 \mathrm{pd})$ bond lengths and the CBS-QB3 binding energies. Dotted lines represent intermolecularly formed H-bonds. 


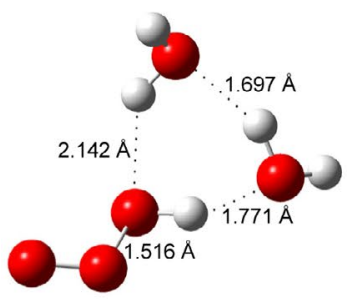

t-HTO-W-W

$D_{0}=11.21 \mathrm{kcal} \mathrm{mol}^{-1}$

$D_{0, \mathrm{~W}}=6.55 \mathrm{kcal} \mathrm{mol}^{-1}$

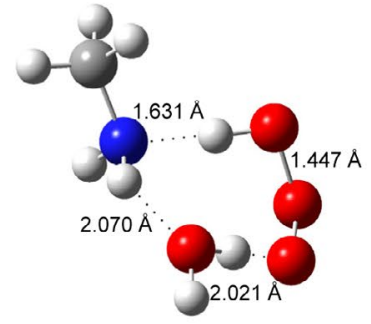

C-HTO-MA-W

$D_{0}=14.87 \mathrm{kcal} \mathrm{mol}^{-1}$

$D_{0, \mathrm{~W}}=5.02 \mathrm{kcal} \mathrm{mol}^{-1}$

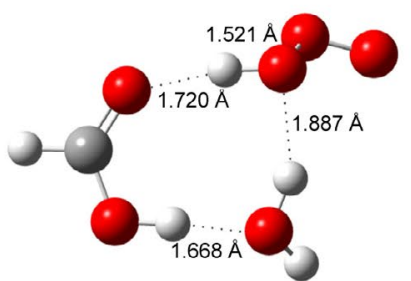

t-HTO-FA-W

$D_{0}=16.97 \mathrm{kcal} \mathrm{mol}^{-1}$

$D_{0, \mathrm{w}}=9.79 \mathrm{kcal} \mathrm{mol}^{-1}$

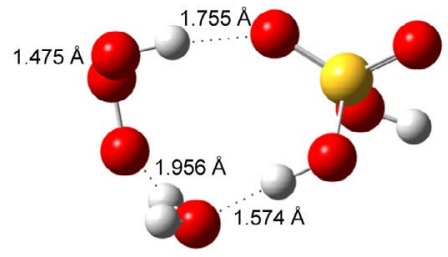

C-HTO-SA-W

$D_{0}=20.79 \mathrm{kcal} \mathrm{mol}^{-1}$

$D_{0, \mathrm{~W}}=11.62 \mathrm{kcal} \mathrm{mol}^{-1}$

Figure 3: Optimised structures of the most stable t-HTO-W-W, c-HTO-MA-W, t-HTO-FA-W and c-HTO-SA-W complexes with the B3LY$\mathrm{P} / 6-311++\mathrm{G}(3 \mathrm{df}, 3 \mathrm{pd})$ bond lengths and the CBS-QB3 binding energies. Dotted lines represent intermolecularly formed H-bonds.

dration of the four stable binary complexes described above. Around two hundred initial guess structures were full geometry optimised and three, five, three and six stable low-energy structures of the HTO-W, HTO-MA, HTO-FA and HTO-SA complexes with water, respectively, were selected. The identified most stable structures of the HTO-W-W, HTO-MA-W, HTO-FA-W and HTO-SA-W are shown in Figure 3, whereas all structures are found in Figure S4 of the Supplementary Material. The binding energies $D_{0}$ and $D_{0, \mathrm{~W}}$ displayed in the figure are related to the monomer interaction process and the process of hydration of corresponding binary complex, respectively.

$t$-HTO- $W-W$ complex. In the most stable ternary complex the conformation of the hydrotrioxy radical unit is changed to the trans arrangement compared to that in the most stable binary structure being cis (c-HTO-W). The inner $\mathrm{O}-\mathrm{O}$ bond of the radical subunit is approximately $0.03 \AA$ shorter than that in the isolated radical. Three $\mathrm{H}$-bonds are formed by the association of the radical with two water molecules. The shortest $\mathrm{H}$-bond with a length of $1.697 \AA$ is formed between two water molecules. Next, the $1.771 \AA$ A long H-bond is a result of an interaction between the radical proton and the lone electron pair of oxygen from the water molecule. The longest $\mathrm{H}$-bond at $2.142 \AA$ results from an interaction of the hydroxyl radical oxygen atom being an electron acceptor and water hydrogen being a proton donor. $\mathrm{t}-\mathrm{HTO}-\mathrm{W}-\mathrm{W}$ is quite stable with a binding energy of $11.21 \mathrm{kcal} \mathrm{mol}^{-1}$. When comparing energies of the ternary complex and the corresponding binary one, we observe that the additional water molecule contributes around $6.55 \mathrm{kcal} \mathrm{mol}^{-1}$ to the stability of the $\mathrm{t}-\mathrm{HTO}-\mathrm{W}-\mathrm{W}$ complex.

$c$-HTO-MA-W complex. Cis configuration of the radical moiety is retained in the hydrogenation of the HTO-MA complex. The radical inner $\mathrm{O}-\mathrm{O}$ bond is again shortened by $0.05 \AA$ A. The c-HTO-MA-W complex is a cyclic structure with three $\mathrm{H}$-bonds. The shortest intermolecular H-bond at 1.631 A results from an interaction between the radical hydrogen and the electron rich amino nitrogen atom. The water molecule acts as an $\mathrm{H}$-donor to the terminal radical oxygen atom, and as an $\mathrm{H}$-acceptor from the amine group, the formed $\mathrm{H}$-bonds are 2.021 and $2.070 \AA$ A long, respectively. Further, calculated binding energy for this complex related to the monomer interaction process is $14.87 \mathrm{kcal} \mathrm{mol}^{-1}$, whereas the additional water contributes $5.02 \mathrm{kcal} \mathrm{mol}^{-1}$ to the stability of the complex.

$t$-HTO-FA- $W$ complex. The hydrotrioxy radical moiety in the complex changes the orientation of atoms when the water molecule is added to the binary HTO-FA complex. The inner O-O bond is shortened by $0.02 \AA$. Three stable intermolecular bonds are formed, resulting in an eight-membered ring structure. The water molecule acts as a proton donor and proton acceptor and forms two 1.887 $\AA$ and $1.668 \AA$ long H-bonds, respectively. The lone electron pair on the carbonyl oxygen atom participates in the 1.720 A long $\mathrm{H}$-bond with the hydrogen atom from the HOOO subunit. The binding energy is predicted to be $16.96 \mathrm{kcal} \mathrm{mol}^{-1}$. Additional water stabilises the most stable HTO-FA complex even further, by $9.06 \mathrm{kcal} \mathrm{mol}^{-1}$.

$c-H T O-S A-W$ complex. Similar to the $\mathrm{t}-\mathrm{HTO}-\mathrm{W}-\mathrm{W}$ and $\mathrm{t}$-HTO-FA-W complexes, the radical moiety changes the orientation in comparison to the corresponding binary complex. As in all the other cases, the inner $\mathrm{O}-\mathrm{O}$ bond in the HTO unit is shortened, in this case by $0.03 \AA$. A strong H-bond, $1.574 \AA$ long, is formed between the hydrogen atom of SA and the lone electron pair on the water oxygen atom, whereas the $\mathrm{H}$-bond with the acid being a proton acceptor is $1.755 \AA$ long. The third intermolecular $\mathrm{H}$-bond is longer, $1.956 \AA$, where water acts as the proton donor and terminal oxygen contributes a lone electron pair to the bond. The c-HTO-SA-W complex with the binding energy of $20.79 \mathrm{kcal} \mathrm{mol}^{-1}$ is predicted to be the most stable ternary structure reported in this study. Water stabilises the HTO-SA significantly, as it contributes $11.62 \mathrm{kcal} \mathrm{mol}^{-1}$ to the stability of the c-HTO-SA-W complex.

\section{2. Vibrational Spectra}

The complete set of harmonic and anharmonic frequencies with IR absorption intensities calculated at 
B3LYP/6-311++G(3df,3pd) level of theory for the both HOOO ${ }^{*}$ conformers and the precursor molecules is collected in Table S1 of the Supplementary Material, where available experimental data for gas-phase molecules of precursors are given for comparison. Figures 4 and 5 show harmonic vibrational spectra for the four most stable binary and the four most stable ternary complexes, respectively.

The intermolecular interactions in complex formation induced new degrees of freedom and consequently new intermolecular vibrational modes which are not present in monomer spectra. An examination of the calculated data shows that the frequencies and IR absorption intensities of $\mathrm{H}$-bonded $\mathrm{OH}$ stretching regions are the most significantly affected by complexation. As expected, a large frequency red-shift is mainly observed for vibration of $\mathrm{OH}$ bonds involved in $\mathrm{H}$-bond formation.

\section{Binary complexes}

$c$-HTO-W complex. The complex has 15 fundamental vibrational modes, 6 of them are related to the free radical and three are related to modes in an isolated water molecule. The remaining six are present due to intermolecular interactions. The most noticeable change in the IR spectrum is a red-shift of $314 \mathrm{~cm}^{-1}$ related to the $\mathrm{OH}$ stretching of the HOOO ${ }^{*}$ radical subunit. This stretching vibration is decreased to $3207 \mathrm{~cm}^{-1}$ in the complex relative to the $3521 \mathrm{~cm}^{-1}$ in the isolated c-HTO, while the intensity of the transition increases to the maximum in the spectra of the complex.

c-HTO-MA complex. This particular complex has even more vibrational modes due to more participating atoms and bonds in the complex formation. When the $\mathrm{OH}$ group from the radical subunit in the complex is compared to the isolated $\mathrm{HOOO}^{\circ}$, it is seen that frequency is red-shifted by $472 \mathrm{~cm}^{-1}$ and is accompanied by a substantial increase in IR absorption.

c-HTO-FA complex. When the anharmonic vibrational frequencies of the $\mathrm{OH}$ symmetric stretch mode of cyclic c-HTO-FA is considered, a shift of $454 \mathrm{~cm}^{-1}$ to the red region of the spectra with increased intensity is observed. The $\mathrm{OH}$ vibration of the formic acid subunit is also shifted to the higher energy by $229 \mathrm{~cm}^{-1}$.

$t$-HTO-SA complex. In this complex, the $\mathrm{OH}$ stretching vibration of the enol HTO and sulphuric acid subunits are also red-shifted compared to the isolated monomers, the shifts are $150 \mathrm{~cm}^{-1}$ and $537 \mathrm{~cm}^{-1}$, respectively.
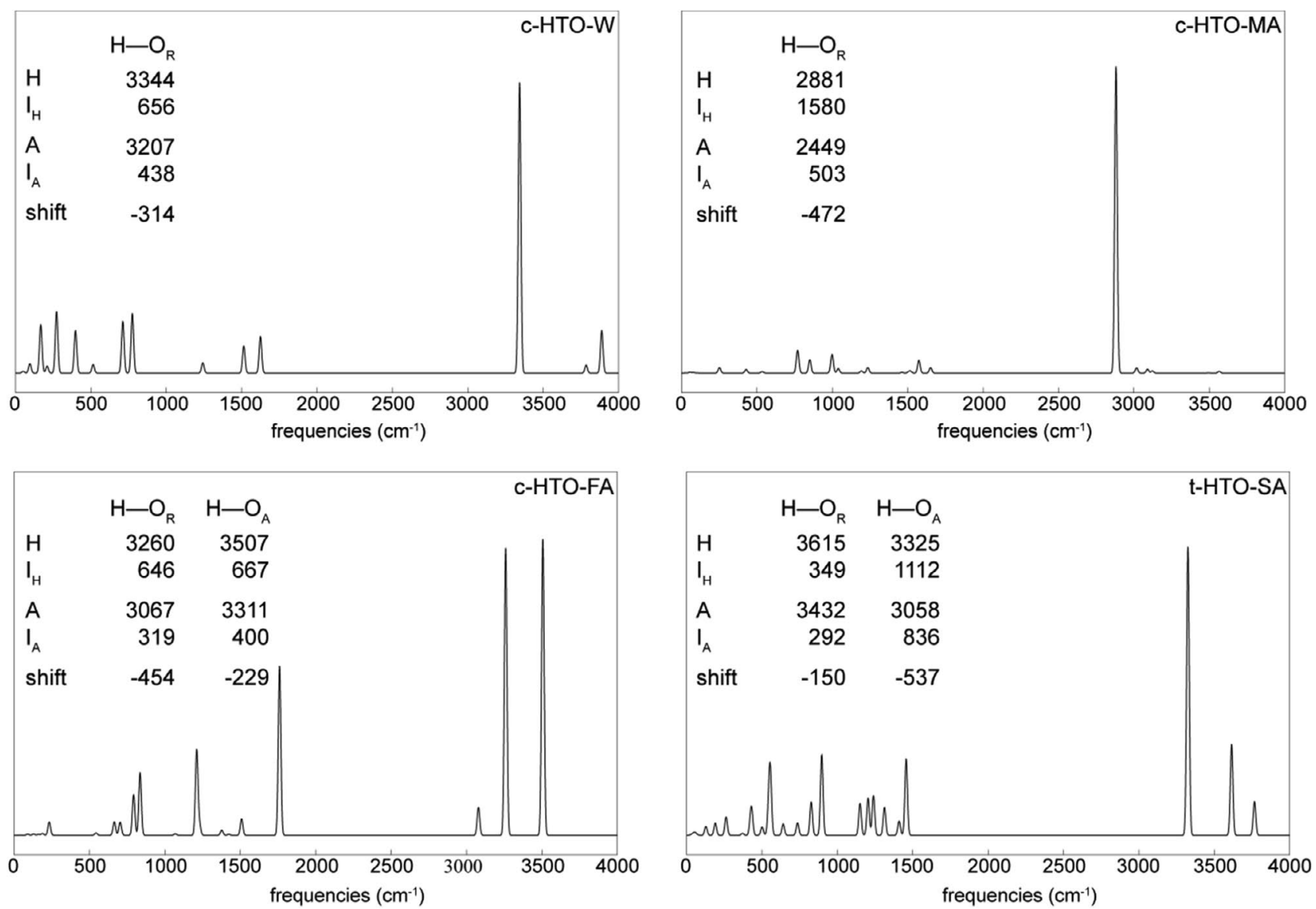

Figure 4: B3LYP/6-3++1G(3df,3pd) calculated IR absorption spectra for the most stable binary complexes. Graphs represent the harmonic absorption spectra, while in the insterted tables the relevant harmonic and anharmonic absorption peaks as well as calculated shifts of anharmonic frequences in $\mathrm{cm}^{-1}$ are summarised. 


\section{Ternary complexes}

In general, ternary complexes have even more vibrational modes due to the three body molecules interactions forming stable complexes.

$t-H T O-W-W$ complex. The radical and both water $\mathrm{OH}$ stretching frequencies are moderately red-shifted; the shifts are $419 \mathrm{~cm}^{-1}, 198 \mathrm{~cm}^{-1}$ and $87 \mathrm{~cm}^{-1}$ compared to the $\mathrm{OH}$ symmetric stretching motions of the radical and water subunits. The vibrational modes are all accompanied by increased intensity.

c-HTO-MA-W complex. The most pronounced change in the vibrational spectrum of the complex with regard to the isolated species is the $419 \mathrm{~cm}^{-1}$ red-shift of the $\mathrm{OH}$ anharmonic stretching frequency in the HOOO moiety. The $\mathrm{OH}$ and $\mathrm{NH}$ stretching of the water and amine moieties are decreased only by $87 \mathrm{~cm}^{-1}$ and $48 \mathrm{~cm}^{-1}$, respectively, implying the less strong participation of water and amino groups in the bonding.

t-HTO-FA- $W$ complex. When the $\mathrm{OH}$-stretching anharmonic frequencies of the $\mathrm{OH}$-stretching in the $\mathrm{t}-\mathrm{HTO}-$ FA-W complex are considered and compared to the isolated species, the red-shifts of $671 \mathrm{~cm}^{-1}, 511 \mathrm{~cm}^{-1}$ and 237 $\mathrm{cm}^{-1}$ are observed for the $\mathrm{OH}$ modes of the radical, formic acid and water moiety, respectively, all involved in the $\mathrm{H}$-bond formation.

c-HTO-SA-W complex. In this specific complex, shifts in three $\mathrm{OH}$ vibrational modes are observed due to participation in the $\mathrm{H}$-bond formation. The $\mathrm{OH}$ stretching in HOOO moiety is shifted by $304 \mathrm{~cm}^{-1}$. Sulphuric acid $\mathrm{OH}$ bond related vibration is decreased by $30 \mathrm{~cm}^{-1}$, and symmetric $\mathrm{OH}$ vibrational mode of water moiety is red-shifted by $180 \mathrm{~cm}^{-1}$.

Evaluated data provides strong evidence that the complex formation of the hydrotrioxy radical with water, methylamine, formic acid and sulphuric acid introduces new intermolecular vibrations. The vibration frequencies of those $\mathrm{OH}$ bonds that participate in $\mathrm{H}$-bonding interaction are generally shifted to lower frequencies, while their intensity absorption bands strongly increase. The other modes in the complexes are similar to that in the isolated monomers.

\section{3. Atmospheric Implication}

Binding energies are important parameters related to the stability of the complexes formed, and the vibrational
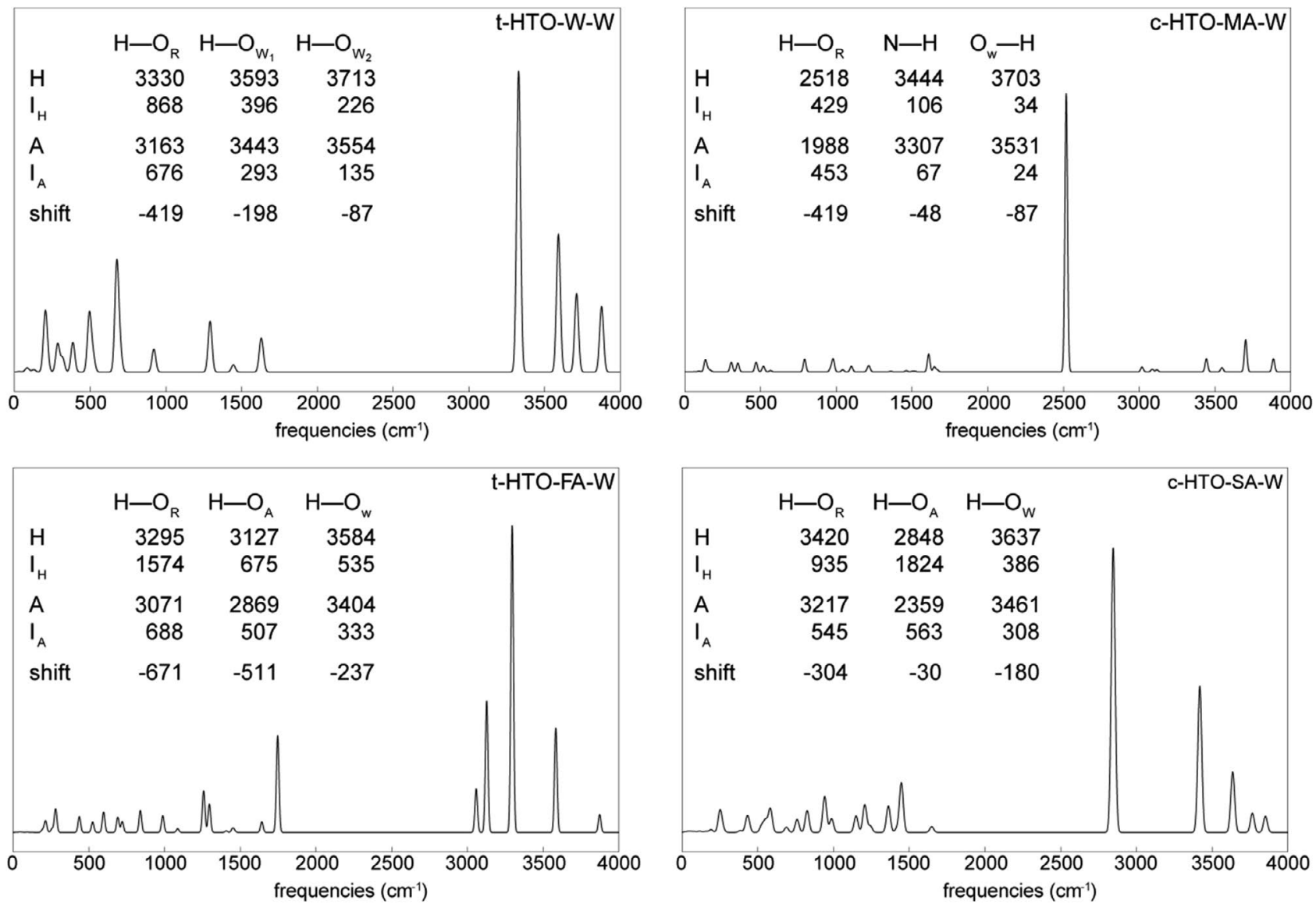

Figure 5: B3LYP/6-311++G(3df,3pd) calculated IR absorption spectra for the most stable ternary complexes. Graphs represent harmonic absorption spectra, while in the inseted tables the relevant harmonic and anharmonic absorption peaks as well as calculated shifts for anharmonic frequences in $\mathrm{cm}^{-1}$ are summarised. 
Table 4: Thermodynamic properties $(\Delta \mathrm{H}, \mathrm{T} \Delta \mathrm{S}$ and $\Delta \mathrm{G})$ in $\mathrm{kcal} \mathrm{mol}^{-1}$ and calculated $\mathrm{K}_{\mathrm{c}}$ values in $\mathrm{cm}^{3}$ molecules ${ }^{-1}$ at different altitude (h) $[\mathrm{km}]$, temperature $(\mathrm{T})[\mathrm{K}]$ and pressure $(\mathrm{p})[\mathrm{atm}]$.

\begin{tabular}{|c|c|c|c|c|c|c|c|}
\hline Complex & $h$ & $T$ & $p$ & $\Delta H$ & $T \Delta S$ & $\Delta G$ & $K_{\mathrm{c}}$ \\
\hline \multicolumn{8}{|c|}{ Binary Complexes } \\
\hline \multirow[t]{4}{*}{ c-HTO-W } & 0 & 298.15 & 1 & -5.42 & -8.40 & 2.98 & $2.8 \times 10^{-22}$ \\
\hline & 0 & 278.15 & 1 & -5.44 & -7.84 & 2.40 & $5.1 \times 10^{-22}$ \\
\hline & 5 & 255.15 & 0.533 & -5.46 & -7.53 & 2.07 & $6.1 \times 10^{-22}$ \\
\hline & 8 & 236.15 & 0.351 & -5.47 & -7.18 & 1.71 & $8.8 \times 10^{-22}$ \\
\hline \multirow[t]{4}{*}{ c-HTO-MA } & 0 & 298.15 & 1 & -9.94 & -9.24 & -0.70 & $1.4 \times 10^{-19}$ \\
\hline & 0 & 278.15 & 1 & -9.97 & -8.64 & -1.33 & $4.4 \times 10^{-19}$ \\
\hline & 5 & 255.15 & 0.533 & -9.99 & -8.25 & -1.74 & $1.1 \times 10^{-18}$ \\
\hline & 8 & 236.15 & 0.351 & -10.01 & -7.84 & -2.16 & $3.4 \times 10^{-18}$ \\
\hline \multirow[t]{4}{*}{ c-HTO-FA } & 0 & 298.15 & 1 & -8.37 & -10.29 & 1.92 & $1.7 \times 10^{-21}$ \\
\hline & 0 & 278.15 & 1 & -8.40 & -9.63 & 1.23 & $4.3 \times 10^{-21}$ \\
\hline & 5 & 255.15 & 0.533 & -8.44 & -9.19 & 0.75 & $8.3 \times 10^{-21}$ \\
\hline & 8 & 236.15 & 0.351 & -8.47 & -8.72 & 0.26 & $1.9 \times 10^{-20}$ \\
\hline \multirow[t]{4}{*}{ t-HTO-SA } & 0 & 298.15 & 1 & -10.02 & -9.45 & -0.56 & $1.1 \times 10^{-19}$ \\
\hline & 0 & 278.15 & 1 & -10.06 & -8.86 & -1.20 & $3.5 \times 10^{-19}$ \\
\hline & 5 & 255.15 & 0.533 & -10.10 & -8.49 & -1.61 & $8.8 \times 10^{-19}$ \\
\hline & 8 & 236.15 & 0.351 & -10.13 & -8.08 & -2.05 & $2.7 \times 10^{-18}$ \\
\hline \multicolumn{8}{|c|}{ Ternary Complexes } \\
\hline \multirow[t]{4}{*}{ t-HTO-W-W } & 0 & 298.15 & 1 & -12.66 & -18.04 & 5.38 & $4.8 \times 10^{-24}$ \\
\hline & 0 & 278.15 & 1 & -12.70 & -16.86 & 4.16 & $2.1 \times 10^{-23}$ \\
\hline & 5 & 255.15 & 0.533 & -12.72 & -16.13 & 3.41 & $4.4 \times 10^{-23}$ \\
\hline & 8 & 236.15 & 0.351 & -12.74 & -15.33 & 2.59 & $1.3 \times 10^{-22}$ \\
\hline \multirow[t]{4}{*}{ c-HTO-MA-W } & 0 & 298.15 & 1 & -15.59 & -18.29 & 2.70 & $4.5 \times 10^{-22}$ \\
\hline & 0 & 278.15 & 1 & -15.65 & -17.12 & 1.47 & $2.8 \times 10^{-21}$ \\
\hline & 5 & 255.15 & 0.533 & -15.71 & -16.40 & 0.69 & $9.3 \times 10^{-21}$ \\
\hline & 8 & 236.15 & 0.351 & -15.75 & -15.61 & -0.14 & $4.5 \times 10^{-20}$ \\
\hline \multirow[t]{4}{*}{ t-HTO-FA-W } & 0 & 298.15 & 1 & -17.94 & -19.69 & 1.75 & $2.2 \times 10^{-21}$ \\
\hline & 0 & 278.15 & 1 & -17.99 & -18.42 & 0.43 & $1.8 \times 10^{-20}$ \\
\hline & 5 & 255.15 & 0.533 & -18.04 & -17.58 & -0.46 & $8.9 \times 10^{-20}$ \\
\hline & 8 & 236.15 & 0.351 & -18.07 & -19.69 & -1.38 & $6.3 \times 10^{-19}$ \\
\hline \multirow[t]{4}{*}{ c-HTO-SA-W } & 0 & 298.15 & 1 & -21.45 & -18.89 & -2.56 & $3.2 \times 10^{-18}$ \\
\hline & 0 & 278.15 & 1 & -21.50 & -17.67 & -3.83 & $4.1 \times 10^{-17}$ \\
\hline & 5 & 255.15 & 0.533 & -21.55 & -16.69 & -4.66 & $3.6 \times 10^{-16}$ \\
\hline & 8 & 236.15 & 0.351 & -21.58 & -16.06 & -5.53 & $4.4 \times 10^{-15}$ \\
\hline
\end{tabular}

spectra provide valuable data for laboratory and atmospheric identification. To provide insightful information into the atmospheric relevance of the complexes the thermochemical properties have also to be evaluated.

The enthalpy $(\Delta H)$, entropy $(T \Delta S)$ and Gibbs free energy $(\Delta G)$ changes for global minimum structures of binary and ternary complexes were calculated as a difference between the values for the complex and infinity separated constituents. These quantities at different atmospheric conditions as noted in the introduction section together with calculated $K_{\mathrm{c}}$ values according to the equation 5 are gathered in Table 4.

An inspection of the table illustrates that both the binary and ternary complex formations are exothermic processes at all studied conditions. The $\Delta H$ value decreases with increasing atmospheric height, but according to the $\Delta G$ value, not all processes are spontaneous. The c-HTOMA and t-HTO-SA binary complexes, are spontaneously formed at all conditions with $\Delta G_{236.15}=-2.16 \mathrm{kcal} \mathrm{mol}^{-1}$ and $-2.05 \mathrm{kcal} \mathrm{mol}^{-1}$, respectively. Only the c-HTO-SA-W ternary complex is formed spontaneously at all studied altitudes with $\Delta G_{236.15}=-5.53 \mathrm{kcal} \mathrm{mol}^{-1}$, while c-HTOMA-W and t-HTO-FA-W have a negative Gibbs free energy value at higher levels of the troposphere. $K_{\mathrm{c}}$ values of the complexes increase with height, probably due to lower pressure and lower concentration of the reactive species. From the equilibrium constants and the gas-phase concentration of molecular species, we have evaluated relative abundance of the particular binary complexes. The reported atmospheric concentrations at $298 \mathrm{~K}$ are as fol- 
lows: $\left[\mathrm{H}_{2} \mathrm{O}\right]=8 \times 10^{17}$ molecules $\mathrm{cm}^{-3}{ }^{17},\left[\mathrm{CH}_{3} \mathrm{NH}_{2}\right]=1 \times$ $10^{7}$ molecules $\mathrm{cm}^{-3} 20,[\mathrm{HCOOH}]=2 \times 10^{11}$ molecules $\mathrm{cm}^{-318}$ and $\left[\mathrm{H}_{2} \mathrm{SO}_{4}\right]=1 \times 10^{7}$ molecules $\mathrm{cm}^{-3}{ }^{18}$. For example, $0.002 \%$ of the HOOO ${ }^{\circ}$ radical is bounded into the c-HTO-W complex at the Earth's surface, while only $4 \times$ $10^{-4} \%$ of the radical forms a binary complex with water at an altitude of $8 \mathrm{~km}$ and $100 \%$ relative humidity. For other complexes the values of relative abundance can go as far as ten decades lower than those calculated for water.

Figure 6 illustrates the computed equilibrium constants at the different temperatures at the ground level and different altitudes of the Earth's atmosphere for the all spontaneous processes. The equilibrium constants for the formation of the bimolecular t-HTO-SA and c-HTO-MA complexes are comparable. A formation of the ternary c-HTO-SA-W complex from monomes appears to be more favourable than the hydration of binay c-HTO-SA complex. The equilibrium constant for the hydration of binary complexes is one decade lower than for the monomer interaction process resulting in the same ternary c-HTOSA-W complex formation. Thermodynamic quantities for the hydration process of binary complexes are listed in the Table S2 of the Supplementary Material. drotrioxy radical with lengths of around $1.75 \AA$, while the complexes with both acids have a cyclic structure with two $\mathrm{H}$-bonds, the second $\mathrm{H}$-bonds are somewhat longer. The binding energies of complexes with methylamine and sulphuric acid are comparable, they approach to $10 \mathrm{kcal} \mathrm{mol}^{-1}$. The addition of water to the most stable dimer complexes resulted in multiple $\mathrm{H}$-bonded cyclic structures with H-bonds of lengths between $1.6 \AA$ and $2.1 \AA$ and stabilised the most effectively the complex with sulphuric acid, with binding energy of $20.8 \mathrm{kcal} \mathrm{mol}^{-1}$.

The present calculations confirmed that large spectral red-shift and enhancement of IR intensities could be used for spectroscopic identification in the atmosphere. In particular, the most substantial red-shift of $671 \mathrm{~cm}^{-1}$ is observed for the $\mathrm{H}$-bonded $\mathrm{OH}$ stretching vibrational mode of HOOO moiety in the hydrated complex involved formic acid.

From the calculated thermodynamic quantities, it should be concluded that a binary complex with methylamine and sulphuric acid, and a ternary complex with sulphuric acid are all formed spontaneously at the Earth's surface to the height of $8 \mathrm{~km}$ in the troposphere. Equilibrium constants of the complexes increase with increasing altitude.

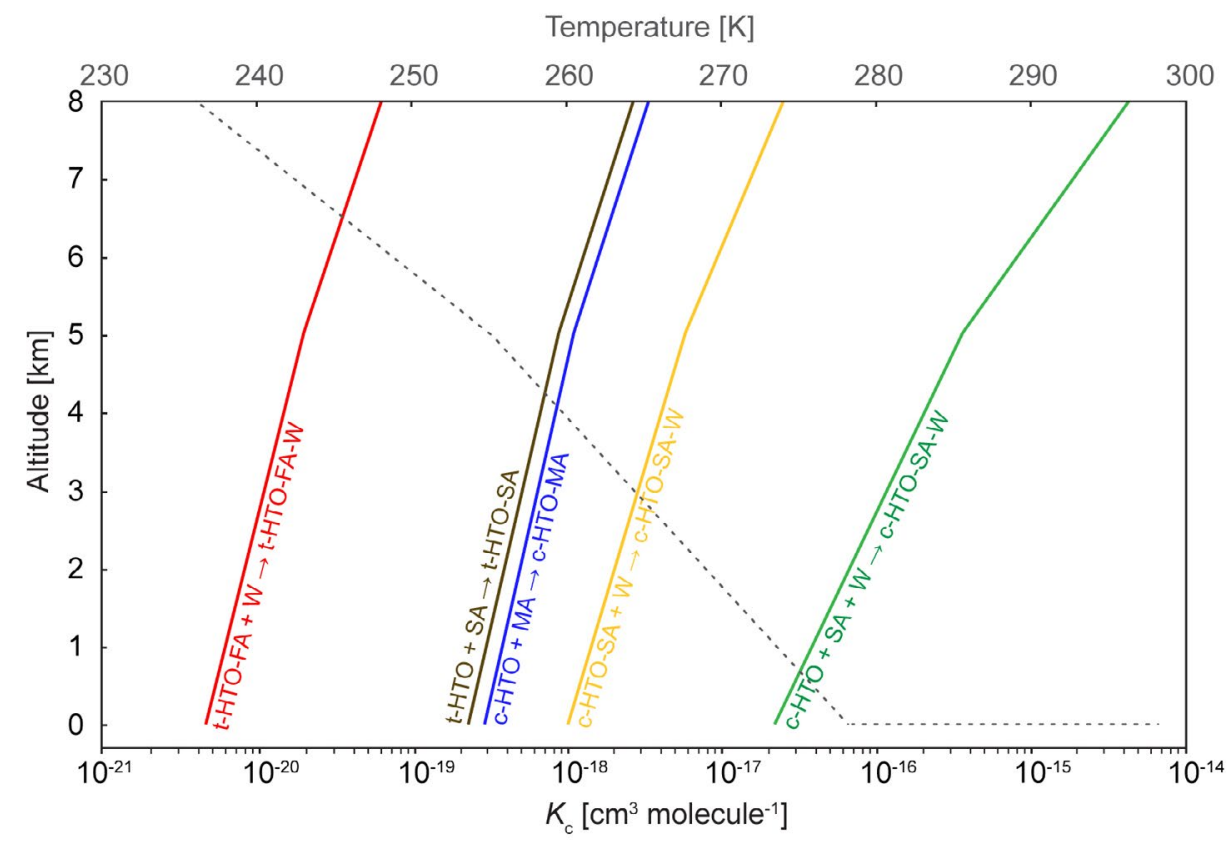

Figure 6: Calculated equilibrium constants, $\mathrm{K}_{\mathrm{c}}$, as a function of the altitude of Earth's atmosphere for the formation of selected processes indicated along each curve on the figure above. The dashed line represents a variation of temperature.

\section{Conclusion}

The hydrogen-bonded complexes of hydrotrioxy radical with water, methylamine, formic acid and sulphuric acid were studied using the $\mathrm{B} 3 \mathrm{LYP} / 6-311++\mathrm{G}(3 \mathrm{df}, 3 \mathrm{pd})$ and CBS-QB3 methods. Our results indicate that due to the negligible energy difference, $0.1 \mathrm{kcal} \mathrm{mol}^{-1}$, either the cis or trans isomer is involved in the complexation. Water and methylamine formed one strong $\mathrm{H}$-bond with the hy-

\section{Acknowledgment}

This research was funded by the Slovene Research Agency, Program grant number P2-0393 and, partly, PR08976. M. D. is grateful to prof. Tomaž Urbič for his contribution to the master's work. 


\section{References}

1. M. C. McCarthy et al., J. Chem. Phys. 2012, 136, 034303. DOI: $10.1063 / 1.3673875$

2. D. G. Semes'ko, S.L. Khursan, Russ. J. Phys. Chem. A 2008, 82, 1277-1282. DOI:10.1134/S0036024408080074

3. K. Bhattacharjee, P. K. Shukla, Struct. Chem. 2018, 29, 11091118. DOI:10.1007/s11224-018-1095-3

4. S. Chalmet, M. F. Ruiz-Lopez, Chem. Phys. Chem. 2006, 7, 463-467. DOI:10.1002/cphc.200500326

5. S. L. Khursan, PATAI'S Chem. of Func. Group. 2014, 1, 1-72.

6. C. Murray, E. L. Derro, T. D. Sechler, M. I. Lester, Acc. Chem. Res. 2008, 42, 419-427. DOI:10.1021/ar8001987

7. R. J. Blint, M. D. Newton, J. Chem. Phys. 1973, 59, 6220-6228. DOI:10.1063/1.1680001

8. M. Speranza, Inorg. Chem. 1996, 35, 6140-6151. DOI:10.1021/ic960549s

9. F. Cacace, G. De Petris, F. Pepi, A. Troiani, Science 1999, 285, 81-82. DOI:10.1126/science.285.5424.81

10. B. Nelander, A. Engdahl, T. Svensson, Chem. Phys. Lett. 2000, 332, 403-408. DOI:10.1016/S0009-2614(00)01280-X

11. K. Suma, Y. Sumiyoshi, Y. Endo, Science 2005, 308, 18851886. DOI:10.1126/science.1112233

12. J. M. Anglada, S. Olivella, A. Sole, J. Chem. Theory Comput. 2010, 6, 2743-2750. DOI:10.1021/ct100358e

13. J. M. Beames, et. al., J. Chem. Phys. 2011, 134, 044304. DOI: $10.1063 / 1.3518415$

14. M. C. McCarthy, et. al., J. Chem. Phys. 2012, 136, 034303. DOI:10.1063/1.3673875

15. J. M. Kim, S. Y. Hong, S. J. Kim, J. Korean Chem. Soc. 2015, 59, 387-396. DOI:10.5012/jkcs.2015.59.5.387

16. D. Cannon, T. Tuttle, J, Koller, B. Plesničar, Comput. Theor. Chem. 2013, 1010, 19-24.

DOI:10.1016/j.comptc.2013.01.009
17. M. B. McElroy: The atmospheric environment: effects of human activity. Princeton University Press, Princeton, United States, 2002, pp. 205-211.

18. R. Zhang et al., Science 2004, 304, 1487-1490. DOI:10.1126/science.1095139

19. L. Yao et al., Science 2018, 361, 278-281. DOI:10.1126/science.aao4839

20. F. Yu, G. Luo, Atmos. Chem. Phys. 2014, 114, 12455-12464. DOI:10.5194/acp-14-12455-2014

21. M. J. Frisch et al., Gaussian 16, Revision B.01. Gaussian, Inc., Wallingford CT, 2016.

22. C. Lee, W. Yang, R. G. Parr, Phys. Rev. B 1988, 37, 785-789. DOI:10.1103/PhysRevB.37.785

23. B. Miehlich, A. Savin, H. Stoll, H. Preuss, Chem. Phys. Lett. 1989, 157, 200-206. DOI:10.1016/0009-2614(89)87234-3

24. . Krishnan, J. S. Binkley, R. Seeger, J. A. Pople, J. Chem. Phys. 1980, 7, 650-654. DOI:10.1063/1.438955

25. J. A. Montgomery, M. J. Frisch, J. W. Ochterski, G. A. Petersson, J. Chem. Phys. 1999, 110, 2822-2827.

DOI:10.1063/1.477924

26. Y. Zhao, D. G. Truhlar, Acc. Chem. Res. 2008, 41, 157. DOI:10.1021/ar700111a

27. K. Raghavachari, G. W. Trucks, J. A. Pople, M. Head-Gordon, Chem. Phys. Lett. 1989, 157, 479-483.

DOI:10.1016/S0009-2614(89)87395-6

28. K. P. Huber, G. Herzberg: Molecular Spectra and Molecular Structure, Van Nostrand Reinhold Company, New York, United States, 1979, pp. 463.

DOI:10.1007/978-1-4757-0961-2

29. S. D. Le Picard et al., Science 2010, 328, 1258-1262. DOI:10.1126/science.1184459

30. C. Murray, E. L. Derro, T. D. Sechler, M. I. Lester, J. Phys. Chem. A 2007, 111, 11592. DOI:10.1021/jp071473w

\section{Povzetek}

Delo povzema študij kompleksov hidrotrioksi radikala $\mathrm{z}$ vodo, metilaminom, mravljinčno kislino in žveplovo kislino z metodama B3LYP/6-311++G(3df, 3pd) in CBS-QB3. Rezultati kažejo, da je razlika energije med cis in trans izomero radikala le $0,1 \mathrm{kcal} \mathrm{mol}^{-1}$, zato smo obe izomeri vključili v preučevanje kompleksov. Voda in metilamin sta v interakciji $\mathrm{z}$ radikalom tvorili eno močno $\mathrm{H}$-vez z dolžino okoli $1,75 \AA$, medtem ko imata kompleksa z obema kislinama ciklično strukturo z dvema H-vezema, dolžini druge H-vezi v kompleksih pa sta nekoliko daljši. Vezavni energiji kompleksov $\mathrm{z}$ metilaminom in žveplovo kislino sta med seboj primerljivi, približujta se $10 \mathrm{kcal} \mathrm{mol}^{-1}$. Dodana molekula vode najbolj stabilnim dimernim kompleksom vodi do tvorbe cikličnih struktur z več H-vezmi z dolžinami med 1,6 in 2,1 Å. Najbolj se stabilizirana kompleks z žveplovo kislino, njegova vezavna energija je $20,8 \mathrm{kcal} \mathrm{mol}^{-1}$.

Z izračuni anharmonskih frekvenc smo pokazali, da je komplekse v ozračju mogoče identificirati z IR spektroskopijo. Zlasti velik premik v rdeči del spektra, pomik $671 \mathrm{~cm}^{-1}$, se pojavi pri OH-nazteznem nihanju v hidratiranem kompleksu $\mathrm{z}$ mravljično kislino. Na osnovi izračunananih termodinamskih količin zaključimo, da se binarna kompleksa $\mathrm{z}$ metilaminom in žveplovo kislino ter kompleks z žveplovo kislino in vodo tvorijo spontano od površja zemlje do višine $8 \mathrm{~km} v$ troposferi. Ravnotežne konstante kompleksov naraščajo z večanjem nadmorske višine. 